\section{UN PUENTE ENTRE ESPAÑA Y PORTUGAL: CARMEN DE BURGOS Y SU AMISTAD CON ANA DE CASTRO OSÓRIO}

\author{
Dra. Concepción Núñez Rey \\ Facultad de Ciencias de la Información \\ Universidad Complutense de Madrid \\ cnunezr@ccinf.ucm.es
}

\section{A BRIDGE BETWEEN SPAIN AND PORTUGAL: CARMEN DE BURGOS AND HER FRIENDSHIP WITH ANA DE CASTRO OSÓRIO}

Copyright: (c) 2014 CSIC. Este es un artículo de acceso abierto distribuido bajo los términos de la licencia Creative Commons Attribution-Non Commercial (by-nc) Spain 3.0.

Recibido: 8 enero 2014. Aceptado: 8 febrero 2014.

RESUMEN: España y Portugal vivieron un tiempo de intenso intercambio cultural a partir de 1915 a través de dos grandes figuras femeninas de ambos países, unidas por fuertes vínculos intelectuales y personales. Ana de Castro fue una escritora muy destacada en la política, en el periodismo y en la literatura lusas desde finales del siglo XIX, y Carmen de Burgos fue la primera periodista profesional española y una de las escritoras más importantes del primer tercio del siglo XX. Ambas compartieron grandes ideales de igualdad para la mujer y de justicia social para todos, unidos a una incesante labor periodística y literaria: Ana de Castro, más como política, Carmen de Burgos, más como escritora. Recordamos aquí la intensa actividad compartida y el amplio eco que encontró en la prensa de los dos países.

PALABRAS CLAVE: España; Portugal; Ana de Castro; Carmen de Burgos; periodismo; literatura; república; feminismo; voto femenino; masonería; Cruzada das Mulheres Portuguesas; Cruzada de Mujeres Españolas.
ABSTRACT: Spain and Portugal experienced a time of intense cultural exchange from 1915 onwards through two major female figures in the two countries who were bound by strong intellectual and personal links. Ana de Castro was a writer prominent in politics, journalism and Portuguese literature from the late 19th century, and Carmen de Burgos was the first professional Spanish woman journalist and one of the most important writers of the first third of the 20th century. They shared the ideals of equality for women and social justice for all, in conjunction with their incessant work in the press and in literary creation: Ana de Castro, more as a political figure, Carmen de Burgos, more as writer. We remember here the intense activity that they shared and the wide echo that it found in the press of both countries.

KEYWORDS: Spain; Portugal; Ana de Castro; Carmen de Burgos; journalism; literature; republic; feminism; feminine vote; Freemasonry; Cruzada das Mulheres Portuguesas; Cruzada de Mujeres Españolas.

PORTUGAL Y ESPAÑA

Portugal [...] la visión del sitio más bondadoso y más fraternal al que podremos huir algún día.

Carmen de Burgos

En Lisboa, en la que se vuelve a sentir el desayuno primero del mundo, me siento por fin feliz. 
A lo largo de la historia, las relaciones entre España y Portugal, a pesar de su vecindad, no gozaron de lo que llamaríamos mutua y plena confianza. Para intentar superar esa fisura, desde el siglo XVIII se desarrolló un largo movimiento de aproximación entre ambos países, que conocemos con el nombre de Iberismo y que alcanzó gran extensión y complejidad a lo largo del siglo XIX. Distintas tendencias ideológicas y distintas concepciones del Estado elaboraron sus propias alternativas en aras de la deseada vinculación. Hubo propuestas de uniones dinásticas y sobre todo hubo magnos proyectos federalistas que desde las filas republicanas propugnaban la integración de los dos estados. Durante el primer tercio del siglo XX, políticos e intelectuales republicanos, españoles y portugueses, revitalizaron el proyecto integrador.

Pero hecha esta mención, no es el desarrollo ideológico y político del llamado Iberismo el objeto de nuestro estudio, como es obvio. Nos proponemos, en realidad, sacar a la luz uno de los momentos en que España y Portugal compartieron muy especiales e intensos intercambios culturales. Y sobre todo, deseamos evocar y ofrecer un testimonio riguroso de dos grandes figuras femeninas, que gozaron en vida del máximo prestigio (aunque no suficientemente recordado hoy), quienes propiciaron y extendieron durante casi dos décadas esos estrechos vínculos entre los dos países. Sus nombres, Ana de Castro Osório y Carmen de Burgos, deben figurar entre nosotros con letras mayúsculas, según hemos de ver. Ambas se sintieron unidas por una honda, inteligente y leal amistad que ennobleció cuantos proyectos compartieron, y que nos ennoblece a nosotros al recuperar su memoria.

Como estudiosa de la vida y la obra literaria de Carmen de Burgos, me corresponde contemplar aquel periodo desde la perspectiva de la autora española; pero el lector portugués evocará al mismo tiempo a numerosos personajes, políticos, literatos o artistas, que protagonizaron las dos primeras décadas de su República. Un tiempo en el que vino a coincidir la amistad fraternal entre Ana de Castro y Carmen de Burgos.

Cuando se encontraron, en 1915 , se hallaban en plena madurez intelectual y vital; ambas arrastraban tras de sí gran fama y prestigio en varios campos, el periodismo, la literatura y el ideario político en favor de diversas causas sociales, muy especialmente en favor de la igualdad de derechos de la mujer. Sus trayectorias personales, en cambio, habían sido bien distintas.

\section{CARMEN DE BURGOS, COLOMBINE}

Si repasamos velozmente la rica y compleja vida de Carmen de Burgos, quien recorrió medio mundo estableciendo vínculos con intelectuales, artistas o políticos, y cuya voz fue solicitada desde las tribunas más prestigiosas, nos asombra descubrir que Portugal significó para ella un afecto esencial, entrañable y permanente, nacido en su infancia y mantenido hasta el final. Con sus propias palabras, la autora evoca lo que los documentos oficiales demuestran: "En mi hogar de Almería, que por ser Consulado de Portugal acariciaba con su sombra la bandera blanca y azul" (Burgos, 1916 d, p. 363). En efecto, don José de Burgos fue nombrado Vicecónsul de Portugal el 24 de diciembre de 1872, y ocupó el cargo durante treinta y siete años. Dos años después de su nombramiento, le fue concedido el grado de Caballero de la Orden del Cristo. Según la autora, su padre mantuvo estrecha amistad con Latino Coelho, figura del republicanismo portugués y uno de los grandes ideólogos del Iberismo.

Aquel vínculo familiar con el vecino país tuvo repercusiones muy hondas en la vida de Carmen, según meditaba ella misma, pasados los años, cuando visitó la redacción de Jornal do Comercio:

tengo con ese periódico una deuda romántica. Quizás le debo a él mi afición al periodismo, a la literatura y a los viajes. Yo aprendí a leer espontáneamente en la plana de anuncios de ese Jornal que iba a perderse en las soledades de mi cortijo de Rodalquilar. La impresión que hacían en mi ánimo las «negritas» rotundas, redondas y gruesas de sus letreros no se ha borrado aún. Bajo ella había siempre grabados unos barcos formando columnas unos debajo de otros. Unos barcos muy negros, con una silueta muy gallarda y muy clásica, algunos con su penacho de humo [...] La plana aquella tenía para mí un valor semejante al de las hojas de aleluyas en que me leían aventuras maravillosas. Yo la relacionaba con los mágicos cuentos de Simbad el marino (Burgos, 1916 d, p. 407).

Sus palabras encierran gran significado, no solo porque revelan su temprana familiaridad con la lengua portuguesa, sino porque ella misma nos descubre que ante aquellas páginas del Jornal su imaginación desplegó las grandes pasiones de su vida: escribir y viajar.

Carmen de Burgos, que había nacido en Almería en 1867 , se convirtió en la primera mujer redactora de un periódico el 1 de enero de 1903, cuando inauguró su columna cotidiana en Diario Universal firmando como Colombine, el pseudónimo que llegó a sustituir a su propio nombre. Desde 1905, su columna pasó a Heraldo de Madrid y se inició su colaboración regular 
en $A B C$; en adelante, a lo largo de los años, su firma apareció en las más diversas publicaciones de dentro y fuera de España. Especial valor tiene aquí para nosotros recordar sus crónicas en el diario lisboeta O Mundo, según veremos más adelante.

Su trayectoria literaria y periodística se había iniciado en Madrid en 1901 y ocupó el primer tercio del siglo XX, hasta su muerte repentina en octubre de 1932, un periodo que viene a coincidir con la llamada Edad de Plata de la literatura española. Carmen de Burgos ocupó un lugar muy destacado siguiendo de cerca las tendencias dominantes. Por edad y por su compromiso regeneracionista, sería la figura femenina de la Generación del 98; a partir de 1910, su defensa del racionalismo y una creciente inquietud estética la aproximan al Novecentismo, manteniendo sólidos vínculos con figuras como Juan Ramón Jiménez o Marañón; y al mismo tiempo conecta en sus obras con las nacientes Vanguardias, hecho propiciado sin duda por la cercanía de Ramón Gómez de la Serna, su compañero sentimental durante veinte años.

En tres décadas, la autora creó una extensa obra: como periodista, miles de artículos en la prensa nacional y extranjera; como escritora, decenas de novelas cortas y largas, y varios ensayos; y como erudita, estudios literarios, biografías, libros de viajes, traducciones, etc.

Alcanzó la popularidad muy pronto, repentinamente, a causa de una encuesta que promovió desde Diario Universal en diciembre de 1903 , en la que solicitaba su opinión a figuras políticas y literarias acerca de la necesidad de una ley de divorcio. El resultado fue un éxito aplastante a favor de la ley, lo que promovió un debate social más amplio. Junto al renombre alcanzado se atrajo para siempre enconados ataques de los sectores sociales más conservadores. Una animadversión de enorme trascendencia, que perdurará más allá de su muerte con el silencio impuesto a su memoria al acabar la Guerra Civil.

\section{SU AFÁN EUROPEIZADOR}

Las resonantes campañas en la prensa reflejan la labor más combativa y pública de Carmen de Burgos, pero lo verdaderamente relevante fue tal vez su afán educador, su deseo de influir en la sociedad proponiendo modelos nuevos, intentando racionalizar el pesado fardo de costumbres y tradiciones, cuestionar hábitos mentales, despertar las conciencias. Una labor de estirpe ilustrada. En el origen de estos artículos está siempre la intención de divulgar una idea o de defender una tesis. Los instrumentos inexcusables son la argumentación y el dato concreto, que se combinan a veces con impresiones subjetivas o sentimientos personales.

Su información sobre los modelos europeos procedía al principio de las lecturas pero, a partir del viaje que emprendió la autora en 1905 por Francia e Italia, los modelos se enriquecen con vivencias intensas y se convierten en el negativo de la sociedad española.

En sucesivos viajes, sus libros y sus columnas se alimentaban sin cesar de la mirada atenta de Carmen de Burgos sobre la Europa de su tiempo, que se convierte para nosotros en la ventana por la que nos asomamos al nacimiento de la sociedad europea del siglo XX. Durante el verano de 1914, en que viajó desde Suiza hasta los países escandinavos pasando por Alemania, encontró por primera vez la palabra clave que definía su percepción de Europa: "esta impresión de bienestar" (Heraldo de Madrid, 4-VII1914). La misma palabra con que se ha designado el modelo social europeo tras la Segunda Guerra Mundial. El estudio de aquella sociedad condensaba la puesta en práctica de todos sus ideales de libertad y tolerancia, una sociedad que mimaba la educación de sus ciudadanos como su mayor tesoro.

En el centro de las preocupaciones de Carmen de Burgos estuvo siempre la discriminación sufrida por la mujer. Su objetivo amplio era situarlas en un plano de igualdad con los hombres, para cuyo fin contemplaba un largo y lento camino en el que era preciso extender su educación y promover su integración en la vida social. La autora utilizó con gran habilidad su columna "Lecturas para la mujer" en Diario Universal, que pasó a ser "Femeninas" en Heraldo de Madrid desde 1905. Se limitaba a dar noticia de las actividades y progresos femeninos en las sociedades más avanzadas de Europa, pero el resultado era la enseñanza y la propuesta de esos modelos, prestando especial atención a todo avance educativo, a todo organismo que dentro o fuera de España capacitase a la mujer para ejercer nuevas profesiones.

En paralelo, divulgaba el tratamiento dado a las mujeres en los Códigos Legal y Penal, recomendándoles a la vez la lectura de esos libros donde "se dispone de nuestra suerte y se reglamenta nuestra vida". Al tiempo que proponía: “El Código no puede quedar anacrónico ni adelantarse a su época; se necesita que sea la expresión exacta de nuestras costumbres y nuestras necesidades; el Código español necesita también una reforma, especialmente en lo que a los derechos femeninos se refiere" (Diario Universal, 9-V-1904). 
Rehuía al comienzo el término "feminismo", pero no hacía sino hablar de sus conceptos fundamentales; entre todos ellos, del sufragio femenino. Hizo una primera mención muy tempranamente, comentando las actividades que Federica Bremer promovía en Suecia en favor de ese derecho ("La mujer y el sufragio", El Globo, 8-XII-1902). En otoño de 1906, la autora acababa de regresar de su primer gran viaje por Francia e Italia, desde donde había enviado sus crónicas para Heraldo de Madrid y para $A B C$. Durante su estancia tomó contacto con organizaciones como el Lyceum Club de París, y creó vínculos de amistad y colaboración con colegas y escritores. Con alguno de ellos como Roberto Bracco compartía una concepción de los ideales del feminismo dentro de un modelo político y social: "Concibe Bracco el feminismo y el antifeminismo desarrollándose paralelamente a dos tendencias más amplias y complejas: la democrática y la conservadora" (Heraldo..., 8-XII-1906). De nuevo en Madrid, Carmen de Burgos se propuso repetir la experiencia del plebiscito, sometiendo a la opinión el voto femenino. Otros diarios españoles y algunos extranjeros siguieron interesados el debate. Iba a ser el primer documento que reflejara el estado de opinión de la sociedad española en torno a ese derecho, pero esta vez el resultado defraudó la expectativa. En sus conclusiones, las cifras eran contundentes: la participación fue de 4.962 votos: a favor, 922; en contra, 3.640: "Queda moralmente derrotado el sufragio femenino" (Heraldo..., 25-XI-1906). Sorprendentemente, muchas opiniones contrarias procedían de los sectores progresistas, que por primera vez manifestaban su temor a la posible tendencia conservadora del voto femenino, un temor que reaparecerá en el famoso debate de las Cortes en el otoño de 1931.

No se desalentó. Infatigable, siguió divulgando las frecuentes acciones de las sufragistas en el escenario europeo. Más allá de nuestras fronteras, también es nuestra autora quien representa al feminismo español. En junio de 1913, solo ella y la condesa de San Rafael son invitadas por el Conseil National des Femmes Françaises para participar en el X Congreso Internacional de la Mujer (París, 2-7 de junio), pero Carmen asiste sola a la cita.

En todos aquellos años, la figura de Carmen de Burgos era ya la de una escritora consagrada que acumulaba una extensa producción literaria junto a una creciente labor erudita, y que era solicitada por las publicaciones más prestigiosas. En sus viajes incesantes, no solo había recorrido Europa, sino que otros trayectos la llevaron hasta Argentina, y más tarde, ya en los años veinte, a México, Cuba, Chile... En todas las tribunas habló de literatura, de arte y, como no podía faltar, de la mujer.

\section{PRIMERAS MIRADAS A LA CULTURA PORTUGUESA}

En la primavera de 1903, pocos meses después de iniciarse como redactora en Diario Universal, Carmen de Burgos rindió un primer homenaje a Portugal, que abrió con espíritu "iberista", lamentando la escasa atención de los intelectuales españoles por la literatura del vecino país:

Y la literatura portuguesa crece, se desenvuelve y se eleva desconocida de nosotros. Sin embargo, ninguna tan importante como ella, puesto que las glorias de los dos países corren tan unidas que en muy pocas cuestiones dejan de formar un solo grupo los hispano-portugueses. Hermanos en origen, en sentimientos, en aspiraciones e ideales, la literatura portuguesa es, entre todas las de los pueblos neolatinos, aquella que más nos importa conocer ${ }^{1}$.

En realidad, el artículo estaba dedicado a reconstruir con breves pinceladas el ancho panorama de mujeres escritoras y artistas: "la admirable cultura de nuestras hermanas portuguesas". Algunas aparecían precedidas por sus títulos aristocráticos, como la duquesa de Palmella o la condesa de Proença-a-Velha; otras, novelistas, pensadoras, poetisas y músicas se sucedían con una breve mención: Cláudia de Campos, Maria Amalia Vaz de Carvalho, Carolina Michaëlis de Vasconcellos, Casilda Pinto Coelho e Castro, Beatriz Pinheiro, Zulmira de Mello, Mafalda Mousinho de Alburquerque, Albertina Paraíso, Guillermina Suggia, Adelia Heinz, Carolina Alzina, Elisa Baptista de Sousa, la vizcondesa de Almeida da Araújo. Y aún sin nominar eran recordadas genéricamente escultoras, pintoras, científicas, filántropas. Dedicó especial atención a la escritora Maria Olga Moraes Sarmento, fundadora del periódico Sociedade Futura, brillante poetisa y miembro de la Sociedad Astronómica de Francia. Carmen de Burgos ignoraba al rendirle este homenaje que Olga Moraes se iba a convertir dos años después, siendo ambas corresponsales en París, en su primera amiga portuguesa. En aquel otoño de 1905 compartieron visitas y experiencias de las que nacían las crónicas que cada una de ellas enviaba a sus respectivos países.

Por encima de todo, destacando entre la sucesión de nombres, aparece ya en aquel primer artículo de 1903 la "notable escritora" Ana de Castro Osório, de quien ignoraba Carmen de Burgos la importancia que había de alcanzar en la historia portuguesa, y quien llegaría a ser, pasados doce años, la amiga más grande 
que la vida dio a nuestra autora. Una honda amistad que solo fue interrumpida por la muerte.

Con la llegada de la República a Portugal en octubre de 1910, nos detenemos de nuevo para recordar las palabras de acogida vertidas por la autora, en las que reitera su homenaje a las mujeres del país:

El triunfo de la causa republicana, tan general y decisivo en el vecino Portugal, nos hace dedicar nuestro recuerdo a las mujeres portuguesas. Parte de nuestro mismo suelo ibérico, hermanos en la historia y en el nacimiento, Portugal y España están unidos por vínculo de afecto, de historia, de semejanzas étnicas y geográficas. [...] De todas nuestras regiones españolas se forma el alma de la mujer española y de la mujer portuguesa. Son los mismos tipos de mujer, bella y sencilla, amante y buena, cultora del hogar, de los recuerdos y del patriotismo.

Las portuguesas han tenido la ventaja de que desde hace muchos años el espíritu liberal ha dominado en sus Universidades. Han sido afortunadas en ese que pudiéramos llamar intercambio de espíritu. Sus Universidades, libres de prejuicios, formaron hombres que las elevaran y dignificaran. Ellas, conscientes y libres, supieron educar y formar a su vez una generación de hombres honrados, patrióticos, geniales.

Geniales he dicho, Portugal tiene hoy los mejores prosistas y poetas europeos ${ }^{2}$.

Esta vez son muy pocas las figuras femeninas mencionadas, entre las que destaca nuevamente Maria Olga Moraes y su incesante actividad europea. Le interesa ahora reflexionar sobre el papel de la mujer en la sociedad y la previa labor de su educación, necesaria para contribuir al bien colectivo, lo que a sus ojos ha conseguido la nación hermana:

Las mujeres portuguesas acaban de dar hermosa muestra de su valor y sensatez. Pero téngase en cuenta que estos ejemplos no se improvisan. Escuela, educación, cultura; no descuidemos estas tres cosas, que formarán nuestros espíritus para ser madres, esposas, educadoras y compañeras. La escuela es la antorcha que alumbra el camino de la regeneración de los pueblos (Ibid.).

Muchos en España escribían ahora sobre Portugal, pero Carmen de Burgos volvía con frecuencia su mirada al país, y no eran solo sus figuras femeninas las que atraían su atención. Meses antes, en el mismo 1910, había publicado una semblanza del escritor Orlando Marçal, quien había impulsado en esas fechas la conmemoración del centenario de Alejandro Herculano, el gran historiador y poeta romántico. Situaba nuestra autora la figura de Marçal entre las jóvenes promesas de la literatura portuguesa, glosando su reciente libro de relatos breves Illuminuras (1908), y lo vinculaba con autores españoles como Andrés González Blanco, Ramón Gómez de la Serna y Emiliano Ramírez Ángel. No había hecho más que empezar la gran labor de difusión que Carmen dedicará en España a los escritores portugueses.

\section{EL ENCUENTRO CON PORTUGAL}

Portugal no fue para Carmen de Burgos un lugar de tránsito en su largo recorrido, sino de llegada, o tal vez, de regreso, si pensamos que desde la lejana infancia el país estuvo siempre en su imaginación. Por causa de la Gran guerra, se remansó en cierto modo el afán viajero que la había llevado por toda Europa hasta los confines de Cabo Norte (1914) y, a través del Atlántico, hasta Argentina (1913). Desde su primera visita en el verano de $1915^{3}$, Portugal se le ofreció como una síntesis de muchas cosas buscadas; como marco, su paisaje y su clima, y más íntimamente, una acogida fraternal de escritores, artistas y políticos de cuyo caluroso afecto disfrutó en adelante. En realidad, el país llegaría a convertirse en su segunda patria, que le ofreció un nuevo hogar: "una esperanza de refugio; la visión del sitio más bondadoso y más fraternal al que podremos huir algún día" (Burgos, 1916 d, p. 385).

Parece conveniente recordar que fue Carmen quien contagió a Ramón Gómez de la Serna la admiración por Portugal, y que muy pronto fue el país donde ambos lograron vivir su ya larga relación amorosa con mayor libertad, lejos de la maledicencia madrileña: "En Lisboa, en la que se vuelve a sentir el desayuno primero del mundo, me siento por fin feliz, y encuentro en su suelo algo de tierra de promisión" (G. de la Serna, 1974, pp. 303).

Cuando llegó a Lisboa en agosto de 1915, Carmen de Burgos era ya muy conocida en los círculos periodísticos y literarios lisboetas. Hacía tiempo que su fama y su prestigio habían traspasado las fronteras españolas como símbolo del pensamiento progresista femenino. Recordemos los brindis y el homenaje de despedida que Magalhães Lima ofreció a la autora en el casino de Algés: siendo "saudada em Carmen de Burgos a Hespanha intellectual e liberal".

El 23 de agosto de 1915, Carmen fue acogida en la portada de A Capital con una larga entrevista titulada, muy familiarmente, "Colombine está en Lisboa", y una elogiosa semblanza de su figura como escritora y como periodista. La autora procedía de Figueira da Foz, en cuya playa había disfrutado algunos días 
de descanso junto a su hija, y llegaba a Lisboa con el propósito de entrevistar a figuras de la política, de la ciencia o del arte. Se alojaba en el Hotel Continental, donde se celebró la entrevista y donde estaba recibiendo en ese momento la bienvenida de Ana de Castro Osório.

Así aparecen por primera vez juntas Ana y Carmen. Parece probable que fuera ese el momento de su encuentro. Parece también que en su conversación no hicieron sino descubrir afinidades, que entre ambas se fraguó de inmediato una corriente de confianza, de simpatía, de reconocimiento, y que juntas miraron desde entonces un largo proyecto común.

No cabe dudar que fue Ana de Castro quien abrió a Carmen de Burgos las puertas de las más altas instituciones de la República, y quien convirtió a sus grandes figuras en amables anfitriones de nuestra autora. En sus visitas a redacciones de periódicos o a museos, en sus desplazamientos a Sintra y Cascais, en las entrevistas a personajes ilustres, en los banquetes de homenaje, y en especial, en la gran fiesta en el barco, recorriendo el estuario al atardecer, anunciada y descrita con gran espacio en la prensa lisboeta:

\begin{abstract}
Un precioso vaporcito, nos esperaba al pie de la escalinata de mármol de la Plaza del Comercio. Sus tripulantes eran todos artistas: literatos, pintores o escultores; las damas todas escritoras, periodistas o actrices como Lucinda Simões y Palmyra Torres.

El barco se ha deslizado entre los ópalos y los dorados del crepúsculo sobre las aguas rizadas y blancas del Tajo. Se ha deslizado con un nadar blando, de dama que pisa sobre alfombras, y parecía que iba tendiendo para nosotros la vista incomparable de Lisboa como una cinta mágica maravillosa (Burgos, 1916 d, p. 408).
\end{abstract}

En la incansable actividad de aquellos días estaba siempre presente la figura de Ana de Castro, en realidad, la verdadera promotora, quien desde la revista mensual A Semeadora, que ella dirigía, reseñaba el día 15 de septiembre, a modo de despedida, la reciente visita de nuestra autora "cujo trabalho e talento honram a raça e a Pátria a que pertence. Grande amiga de Portugal [...] conhece toda a nossa literatura e estima o progresso e a felicidade do nosso povo com um grande carinho e interesse fraternal".

Poco antes, desde su llegada a Madrid, Carmen de Burgos había comenzado a publicar en Heraldo de Madrid sus artículos "De Portugal". Se sucedieron las principales figuras políticas del país, de la naciente República. Todos eran intelectuales humanistas cuya calidad personal sabe transmitir nuestra autora con entusiasmo y admiración, seducida además por la sociedad futura que están construyendo.

Magalhães Lima ${ }^{4}$ inauguró el día 7 la nueva sección, en la que Carmen presentaba al personaje e iniciaba un diálogo desgranando los diversos temas de mayor interés en aquel momento histórico. El político portugués recordaba la buena acogida en España de su libro La Federación Ibérica, su deseo de acercamiento entre los dos pueblos, y evocaba los tiempos en que convivió con grandes políticos españoles "de los que tanto aprendí: Figuerola, Castelar, Salmerón, Pi y Margall, Costa, Giner de los Ríos" (Heraldo..., 7-IX-1915). Del Presidente de la República en funciones, Teófilo Braga $^{5}$, destacó Carmen su figura de sabio más que de político, que había ejercido siempre como Catedrático de Literatura. Cerró con admiración su semblanza ante un político "que no intenta torcer los verdaderos cauces de la vida, que contempla tanto como gobierna, que a todo le concede su natural libertad, que busca para su punto de vista una perspectiva de ciudadano sin alto cargo". Un símbolo y un ejemplo. Le siguió la figura de Bernardino Machado ${ }^{6}$, quien iba a relevarlo en la presidencia. Se declaró profundo conocedor de España y "defensor de la aproximación espiritual de los dos países"; amigo de Salmerón, de Morote, y muy especialmente de Giner de los Ríos, quien había fallecido el 18 de febrero 7 . Le enorgullecía el nombramiento de Profesor Honorario de la Institución Libre de Enseñanza, aunque era en Portugal Catedrático de la Universidad de Coimbra, y agradecía la concesión de las grandes cruces de Isabel la Católica y de Carlos III, recibidas del gobierno español.

En las entrevistas figuraron también algunas mujeres, como la periodista Virginia Quaresma, o como Regina de Quintanilha, la primera abogada del país. La semblanza final, llena de encomio, la dedicó a Ana de Castro Osório, convertida ya en su gran amiga: "La gran escritora portuguesa doña Ana de Castro Osorio presenta en sí el mejor ejemplo de la importancia del papel que la mujer representa en la vida pública de una nación. [...] admiro en ella la representante de todas esas mujeres ilustres del presente y de la Historia" (Heraldo..., 30-X-1915).

Ana evocó con sus palabras el papel de su marido, quien estimuló su labor literaria y sus ideales republicanos. Recordó los avances logrados en poco tiempo a favor de la mujer, atribuyéndolo "a que nosotras nos hemos interesado mucho por la vida pública". Y ella misma resumió el motor de su vida:

yo que amo tanto la literatura y el arte, no comprendo la realización de la belleza como el fin principal o 
único, yo estoy enamorada de la lucha por la libertad, por los derechos de nuestro sexo, por todas las grandes reformas sociales. Es quizás que cuando se ha vivido en un periodo de entusiasmo tan ardiente nos gana por completo la causa de la humanidad y en ella vemos la suprema belleza (Ibíd.).

Un año después, en su libro Peregrinaciones, Carmen volvió a la figura amiga con una nueva semblanza en que intentaba condensar su larga trayectoria:

la escritora portuguesa más representativa [...] ha escrito novelas y libros llenos de arte, y tiene una labor enorme en artículos de periódico y conferencias. Ella dirige A Semeadora y la Casa Editorial Para los Niños, de que es fundadora. [...] Presidenta del Gremio $\mathrm{Ca}$ rolina Angelo y de la Liga Republicana, luchó denodadamente para la implantación de la República, como ahora se ocupa en la Cruzada. Esta mujer excepcional ha influido en la ley del divorcio, en la reforma de los códigos (Burgos, 1916 d, p. 383).

\section{ANA DE CASTRO OSÓRIO}

Doña Ana de Castro era una de las figuras más respetadas e influyentes de la naciente República portuguesa, que tenía tras de sí un largo recorrido en la política, la literatura y el periodismo, y una meta esencial, la defensa de los derechos de la mujer, unida a la protección de la infancia. Una de sus primeras acciones, en edad juvenil, fue imprimir folletos explicativos sobre la conveniencia de la lactancia materna y distribuirlos entre las obreras de las fábricas de conservas de Setúbal ${ }^{8}$.

Un año antes de su encuentro con Carmen de Burgos había enviudado del poeta Paulino de Oliveira, su esposo desde $1898^{\circ}$, a quien acompañó a Brasil en 1911 cuando fue nombrado Cónsul. Cerraba una etapa repleta de acciones pioneras, de proyectos convertidos en conquistas. Siendo muy joven, fundó en 1897 la Casa Editora para as Crianças, un instrumento esencial al servicio de sus ideales educativos y una gran labor en la historia de la Literatura portuguesa, pues Ana de Castro recogió y reelaboró los relatos populares de la tradición oral.

Escribió numerosos ensayos sobre educación, política ciudadana o sobre la defensa de los derechos de la mujer. Ya en 1905 publicó el libro As mulheres portuguesas, documento fundamental para la historia del feminismo luso. En el plano político fue una gran activista, promotora y fundadora de organizaciones feministas, muchas veces situada en un aparente segundo plano. Fue iniciada en 1907 en la Logia Humanidade, que en ese año dejaba de ser Logia de Adopción y al- canzaba estatuto de independencia. Mas tarde pasó a ser Venerable de la Logia Carolina Angelo con el nombre simbólico de Leonor de Fonseca Pimentel ${ }^{10}$.

Apoyada por el Partido Republicano Portugués, fundaba el 28 de agosto de 1908 la Liga Republicana das Mulheres Portuguesas (LRMP) en un acto presidido por ella misma, en el que actuaron como secretarios Magalhães Lima y Bernardino Machado, prohombres de la inminente República. Una vez proclamada en 1910, Ana intervino decisivamente en la elaboración de la ley de divorcio. A partir de 1911, regresó desde Brasil periódicamente para continuar con su labor, pero se estableció definitivamente en Lisboa con sus dos hijos tras la muerte de su marido en 1914. En ese año, Portugal entraba junto al bando aliado en la Primera Guerra Mundial.

Desde este punto, regresamos a su encuentro con Carmen de Burgos, momento en el que Ana se proponía crear una nueva organización que agrupase a las mujeres al servicio de la República; nació así en 1916 la Cruzada das Mulheres Portuguesas (CMP), con Elzira Dantas, esposa de Bernardino Machado, como Presidenta y la propia Ana de Castro como Secretaria General. Pretendían ocupar el vacío dejado por los hombres a causa de la guerra y prestar ayuda a las viudas y a los huérfanos causados por el conflicto. En el artículo primero de sus estatutos se define como: "institução patriótica e humanitária destinada a prestar assistência material e moral aos que dela necessitam por motivo do estado de guerra com a Alemanha" (Castro, 1916).

En un discurso de 1918, pronunciado durante la inauguración de la primera Escola Profissional Feminina, Ana subrayaba el significado feminista de la Cruzada:

demonstrar que há mulheres em Portugal e mais haverá quando todos os homens compreendam... que auxiliar a obra inteligente e autónoma da mulher, honrando e dignificando a sua acção é a melhor forma de ser patriota (Castro, 1918).

Según veremos, la organización iba a tener singular trascendencia para el feminismo español a través de Carmen de Burgos; ella misma llegará a pertenecer al grupo portugués y, más importante aún, fundará la Cruzada de Mujeres Españolas en el verano de 1920.

\section{PORTUGAL EN LA LITERATURA DE CARMEN DE BURGOS}

Las visitas al país de Carmen y Ramón se sucedieron con creciente frecuencia a partir de 1916. En aquel verano descubrieron "Praia das Maçãs", su primer rincón 
entrañable y secreto. Cuando regresaron a Lisboa, se produjo el reencuentro con las figuras de la República entrevistadas el año anterior. Se celebró una cena en el palacio de Belém en compañía del presidente Machado, de su familia y de algunos ministros, sobre la que Carmen dio amplia noticia en Heraldo. En la anterior entrevista de 1915 construyó la imagen del político; esta vez atendió al Machado íntimo, casado con doña Elzira Dantas, a su larga descendencia de quince hijos, sus evocaciones de España, su satisfacción por la posición de su país frente a la guerra (Heraldo..., 21VIII-1916).

Se repitieron de nuevo las gratas veladas en el salón familiar de Ana de Castro, donde el padre, antiguo magistrado, junto a los hijos de doña Ana, sus hermanos y sus invitados se entretenían con la música y la poesía. Carmen y Ramón disfrutaron de aquellos amigos, recordando que también Larra había sentido lo mismo: "esos amigos de Portugal que aún hoy siguen siendo la verdadera especie de los amigos leales y educados, de los amigos ideales" (Gómez de la Serna, 1918, p. 374).

A su regreso, la autora tituló "Serenidad" la primera crónica para Heraldo de Madrid (19-VIII-1916), destacando la impresión que producía el país a pesar de verse inmerso en la guerra europea: "la posesión de sí que despliegan los pueblos conscientes de su destino". Resumió también los últimos progresos de las mujeres: la labor de la Cruzada y los nombramientos de algunas para puestos de responsabilidad, como Ana de Castro, convertida recientemente en Inspectora de Trabajo. Ve también aproximarse la conquista de todos los derechos civiles y políticos, incluso el voto.

Meses después, José Osório de Castro, hijo de Ana, comentaba con entusiasmo desde A Semeadora (15I-1917) el libro de Carmen Peregrinaciones, en el que recogía su largo periplo de 1914 hasta el Ártico y añadía un largo capítulo dedicado a Portugal:

um livro feito de impressões sugestivas, que faz ressaltar a impressão da nossa vida e da nossa arte, da beleza da nossa terra. [...]

Ao seu grande valor intelectual junta-se a sua extraordinária actividade e uma raríssima persistência no trabalho que tem contribuído para o seu grande renome em toda a Península, América e mais países da Europa, onde é o nome mais lido da Espanha moderna.

Desde 1916, Carmen ambientó en Portugal muchas de sus novelas, casi una decena; a veces, los argumentos serán solo un pretexto para continuar su exploración del país. De los primeros viajes a Portugal nos dejó la autora muchos datos concretos en el amplísimo capítulo que les dedicó en Peregrinaciones, donde alcanzó a incluir sus vacaciones veraniegas de ese mismo 1916. Años después, según veremos, escribirá la novela La Flor de la Playa (Burgos, 1920 a), recreando la intensa experiencia de aquel primer verano en que disfrutó junto a Ramón de un rincón apartado llamado "Praia das Maçãs" ("la más escondida de sus playas"), un lugar digno de una leyenda. El proyecto de la pareja protagonista de hacerse un hotelito para sus vacaciones veraniegas sería la primera mención de la que Ilegará a ser "El Ventanal", la famosa casa que en 1923 Ramón y Carmen se hicieron construir en Estoril.

Varios relatos se situaron en Lisboa o en el estuario, entre Estoril y Cascais, y muchos de ellos forman parte de las obras más experimentales y vanguardistas que escribió nuestra autora. Don Manolito (1916 b) fue uno de ellos, repleto de referencias autobiográficas, donde se inserta un relato dentro de otro, para contener en realidad un homenaje a la figura de don Manuel García del Castillo, el anciano militar español exiliado, contertulio de la casa de Ana de Castro. En Lisboa se sitúa la novela Los amores de Faustino (1920 b), de nuevo enmarcada por elementos autobiográficos, donde dos amantes, que han visitado varios zoológicos de Europa, descubren en el de Lisboa a una pareja de chimpancés enamorados; el macho Faustino, en su humanización, llega al extremo de dejarse morir por la pérdida de su amada.

A la histórica Beja nos lleva El hastio del amor (1923), donde a modo de collage insertaba la traducción de las famosas cartas de amor de Mariana Alcoforado (1640-1723), dirigidas al mariscal francés Noel Bouton de Chamilly; en nota de la autora: "Estas cartas son las auténticas de la monja portuguesa Sor Mariana Alcoforado, célebres en la literatura de todos los idiomas, y que por primera vez se traducen al español" (Burgos, 1923, p. 11). La novela no es solo un ejemplo de texto inserto en otro: las cartas reales se enmarcan en un contexto inspirado en otro relato, Les liaisons dangereuses, donde la lectora de las cartas Luisa de la Vallière se modela en Madame de Tourvel y Bouton de Chamilly en Valmont.

El espacio del estuario es escenario de un importante experimento narrativo, El suicida asesinado (1922 a), donde un enigma policiaco es resuelto mediante una sucesión de descripciones del mar; fue un anticipo de los recursos del Nouveau Roman.

A Estoril nos lleva la novela El retorno (1922 b), haciendo protagonista a su naciente sociedad mundana 
("La naturaleza había formado aquel lugar para sugerir el sueño de grandeza de un dichoso rival de Monte Carlo"). Un selecto grupo de burgueses distrae su ocio indagando en el mundo de las experiencias esotéricas, en torno al cual se desarrolla el argumento. En su relato afirma la autora la proliferación en Lisboa de grupos de espiritistas y de teosofistas.

En Figueira da Foz situó Los míseros (1916 a), recreando el ambiente grandioso de su playa. Puede decirse que el orden de publicación reproduce los itinerarios de la autora; como sabemos, fue Figueira su primer lugar de veraneo en Portugal en 1915. Descendiendo hacia el sur, en Coimbra ambientó la novela Las Tricanas (1916 c), escogiendo para el argumento a este colectivo de mujeres que representaba una arcaica y bien organizada forma de servilismo sexual y doméstico.

El conjunto de novelas, que nos ofrecen un vivo retrato del Portugal de comienzos del siglo XX, y donde rastreamos innumerables referencias autobiográficas de Carmen con Ramón y de sus entrañables amigos en el país, se completa con más de un centenar de artículos que la autora escribió en la prensa española, no solo en Heraldo. Recordemos especialmente los documentos que sobre el arte, las costumbres y la historia portuguesas ella elaboró y divulgó en la prestigiosa revista La Esfera: los castillos de Sintra, los encajes de Peniche, la Orden de las Comendadeiras de Santiago, la espadelada de Viana do Castelo, el palacio de Queluz o los palitos de Sarvão, el arte, la historia y la intrahistoria de Portugal.

En 1920 emprendió Carmen una importante empresa literaria, la difusión de la reciente literatura portuguesa a través de la revista mensual Cosmópolis, nacida en los círculos del Ultraísmo español. Fue dirigida por Enrique Gómez Carrillo, gran amigo de Carmen y colaborador en París de Rubén Darío para dirigir Mundial Magazine. Las páginas de Cosmópolis se ocupaban sobre todo del inquieto panorama literario europeo incluyendo una sección de poesía de las vanguardias hispanoamericanas. La autora abrió su sección "Crónica literaria de Portugal"11 con un estudio de la figura de Eça de Queiroz. En realidad, se remontaba a los orígenes de la literatura portuguesa, en el punto en que se confundía con la española, para resumir brevemente la trayectoria que llegaba a la novela realista del autor:

He creído un deber empezar por esta gran figura, a la que se le deben todos los homenajes, para continuar estudiando los diferentes géneros y figuras de la literatura portuguesa, que presenta complejos aspectos, hasta lle- gar a esta generación interesantísima, los novos (los jóvenes) que ahora luchan y entre los cuales hay nombres que son una esperanza de gloria para la nación hermana (Cosmópolis, septiembre de 1920, p. 46).

La propia Carmen participó poco después en la edición de Cartas de Inglaterra ${ }^{12}$, traducida por Andrés González Blanco, donde incluyó como prólogo su más extenso estudio del autor, una labor considerada la mejor biografía de Eça de Queiroz hasta aquella fecha.

Dedicó a los "Poetas Modernos" su siguiente estudio en Cosmópolis, reuniendo los nombres más destacados al tiempo que señalaba la fuerza renovadora con que se sucedían las tendencias en la lírica portuguesa. Seleccionó en primer lugar a Camilo Pessanha y su mundo de vagos ensueños, que relacionaba con el primer Juan Ramón Jiménez. Seguido del simbolista João de Castro, el vanguardista António Ferro, al que equiparaba "por lo juvenil y lo arbitrario" al espíritu de Ramón. Los sucesivos estudios fueron ofreciendo como una revelación la gran literatura portuguesa, poco atendida en España, pero que participaba, trazando su propio camino, en las grandes corrientes de la literatura europea. Lo descubrieron Carmen y Ramón, pero fue ella quien se propuso divulgar con fervor aquel tesoro en los medios literarios españoles. Se sucedieron Guerra Junqueiro, Eugénio de Castro, Teófilo Braga, Gomez Leal, João de Deus, Carolina Michaëlis, João de Barros... En su último trabajo hizo una breve semblanza de "El futurista Sá Carneiro"... En el número de julio (№ 31) incluyó una reseña del libro de Ana de Castro La princesa muda, ilustrado por Leal da Câmara, gran amigo de ambas autoras, y ya a la venta en Madrid, traducido por la propia Carmen de Burgos. También recogía la aparición de Los mutilados de guerra, obra editada por la Cruzada de Mujeres Portuguesas.

Carmen reunió rigurosa información y textos representativos para ofrecernos en Cosmópolis una novedosa panorámica de la moderna literatura portuguesa.

\section{LOS LAZOS INSTITUCIONALES CON PORTUGAL}

Los vínculos entre Carmen y Portugal se estrecharon en 1919. Durante un tiempo, las dificultades se sucedieron en el país; a los problemas de la guerra vino a añadirse el pronunciamiento militar de Sidonio Pais el 5 de diciembre de 1917, quien destituyó a Bernardino Machado y persiguió con durísima represión a los dirigentes anteriores. El final de la guerra europea casi coincidió con el asesinato del dictador, de modo que en las celebraciones por la victoria aliada habían regresado al poder los líderes republicanos amigos de 
Carmen. Ella era la fiel amiga de la República Portuguesa, que hablaba en España de sus escritores, de su arte, de sus políticos, de su progreso social, y va a ser recompensada con grandes honores por diferentes sectores del país.

El 14 de julio de 1919 presenció desde la tribuna presidencial, junto al gobierno, en el grupo de la Cruzada de Mujeres, el gran Desfile de la Victoria, paralelo al que se celebraba en París ese mismo día (Heraldo..., 21-VII-1919). Muy poco después se inició el proceso de su condecoración. El Gobierno de la República firmaba el Decreto el 12 de agosto:

\section{Hei por bem Decretar, sob proposta do Ministro dos Negócios Estrangeiros, que seja condecorada com o Grau de Comendador da Ordem de S. Tiago da Espa- da, a escritora e jornalista espanhola Dona Carmen de Burgos. \\ O Ministro dos Negócios Estrangeiros, assim o tenha entendido e faça executar. \\ Paços do Governo da Republica, aos doze de Agosto de mil novecentos e dezanove ${ }^{13}$.}

De nuevo compuso la autora con sus entrevistas a los miembros del gobierno, de una generación más joven que la de Bernardino Machado, una gran crónica del proyecto político portugués, que era difundido en la sociedad española a través de Heraldo. Los nuevos ministros explicaban sus planes para aplicar el ideario de modernización y progreso de su país, que podía resumirse en la vieja frase del Regeneracionismo español, "despensa y escuela", y todo su contenido parece un anticipo de la preocupación dominante en la futura Segunda República Española. Entre los entrevistados, el Presidente Sá Cardoso, seguido por el Presidente de la Cámara de Diputados Domingo Leite Pereira, el Ministro de Instrucción Pública Joaquim de Oliveira, el Ministro de Trabajo José Domingues dos Santos; y en tertulia con Magalhães Lima y Ana de Castro, entrevistó al Ministro de Agricultura César de Lima Alves, quien explicó sus proyectos de mecanización del campo, de racionalización de la producción, de replantación forestal, de canalizaciones de agua y de creación de Escuelas de industrias agrícolas. Carmen se deleitaba: "Escucho con placer todas estas palabras [...] este suelo, todo flores, verdadero jardín de la península, entrará en una era de producción y de desarrollo admirables" (Heraldo, 23-IX-1919).

Entre todos ellos aparecía entrevistada doña Ana de Castro para dar cuenta de los grandes servicios prestados por la Cruzada das Mulheres Portuguesas, el papel activo de las mujeres en Portugal, la influencia benéfica de Inglaterra y Francia en sus costumbres, su grado de europeización frente a las españolas. Ana de Castro era la figura que destacaba, un auténtico símbolo. La amplitud de su acción en la Cruzada abarcaba la ayuda directa a los más desprotegidos tanto como la elaboración de estudios para orientar sólidamente las reformas legales: "Crear trabajo, estudiar las condiciones sociales, moralizar y educar preparando un futuro más equilibrado y más feliz es la obra admirable de las mujeres de Portugal" (Heraldo..., 13-VIII-1919).

Desde aquel verano, Carmen fue invitada a colaborar con el diario $O$ Mundo para realizar una labor inversa, la de difundir en Portugal aspectos políticos y culturales de la vida española:

Aproveitando a recente estada em Lisboa da ilustre escritora espanhola e nossa amiga Carmen de Burgos [...] convidámo-la a colaborar no Mundo com uma crónica semanal, ao que logo acedeu gentilmente, enviandonos já o primeiro desses artigos, que amanhã será publicado. [...] Amiga dedicada de Portugal, tendo-nos prestado relevantes serviços, a brilhante redactora do Heraldo de Madrid é uma mulher de letras na mais alta significação deste termo, considerada em toda a parte onde tem feito brilhar os seus dotes intelectuais. É com o máximo regosijo que anunciamos a colaboração assidua de Colombine (18-X-1919).

Su columna "Coisas de Espanha. Crónica de Colombine", que inauguró el 19 de octubre de 1919, se mantuvo durante más de dos años. En general, reunía en cada crónica un contenido misceláneo sobre temas políticos y culturales sometidos a reflexión crítica, y prestaba especial atención a los problemas que podían afectar a ambos países. En ocasiones cambiaba su título por "Figuras de Espanha", bajo el cual incluía entrevistas con los hombres más destacados dentro de los sectores progresistas y de izquierdas. Las inauguró Julián Besteiro, líder del Partido Socialista, seguido por figuras del republicanismo español como Luis de Zulueta o Melquiades Álvarez. Se completaba así el significado de Carmen de Burgos como puente entre los dos países, entre las dos culturas, o como una ventana por la que podían mirarse con respeto y cordialidad españoles y portugueses. En realidad, ella actuó como punto de encuentro de un universo de ideas compartidas.

En enero de 1920, Carmen llegó a Lisboa, invitada que el gobierno portugués, para impartir un curso de Literatura Española antigua y moderna en la Facultad de Letras de la Universidad de Lisboa, pero llegó muy afectada por su enfermedad cardiaca. Junto a Ramón se instaló durante meses en Estoril, desde donde 
acudía en tren a Lisboa para impartir el curso. En sus artículos contemplamos una panorámica de la ribera del estuario, su variedad de plantas, su lujuriosa vegetación: "Es una primavera en pleno invierno a la orilla del Tajo [...] es más bella que la costa Azul, más florida, más cálida" (Heraldo..., 20-V-1920). Y vemos nacer la cosmopolita Estoril: "Así que esté acabado de construir el hermoso parque y el suntuoso casino, Monte Carlo y Niza van a tener un rival temible" (ibid.). Sus crónicas en Heraldo se llenaban de figuras de la vida portuguesa. Hubo una crisis de gobierno, y Carmen entrevistó al nuevo Presidente, el coronel Antonio María Baptista (26-III-1920). En otra elogiaba a su gran amigo Leal da Câmara: "el caricaturista tiene que ser un literato que se expresa sin palabras, un crítico que dibuja ideas, un satírico que hiere y un humorista que mueve a la risa" (6-III-1920). O la figura de "El buen Juez", don Juan Baptista de Castro, padre de Ana, homenajeado en su reciente fallecimiento por haber concedido el voto a una mujer, la doctora en medicina Carolina Angelo (8-IV-1920).

Durante el mes de mayo se produjo el mayor acontecimiento de la estancia de Carmen en Lisboa, el ciclo de conferencias que pronunció en el "Salão Nobre da Academia de Sciencias". Los periódicos de ambos países describieron la brillantez con que se celebraron los actos y recogieron su repercusión pública: en las principales librerías fueron expuestos los libros de la autora y en la más céntrica, Portugália, se exhibía una copia de su retrato pintado por Romero de Torres. El día 7 de mayo presidió la primera conferencia Teófilo Braga, acompañado por el Ministro de Instrucción y por el Embajador de España. Asistían al acto el ex presidente Bernardino Machado y su esposa, ministros, escritores y artistas. Carmen disertó sobre "O Romantismo espanhol e Mariano José de Larra", describiendo su vida y sus obras, su contacto con Portugal y su significado en la historia de la literatura española.

Días después, Carmen recibió un homenaje de la Cruzada de Mujeres Portuguesas en su sede del Palacio del Marqués de Pombal. Presidió el acto doña Elzira Dantas, junto a Ana de Castro y Beatriz Magalhães. Se recordó la labor de la Cruzada, se ensalzaron los méritos de Carmen de Burgos y Leal da Câmara agradeció la ayuda de la Cruzada para su proyecto de "Aldeia Portuguesa na Flandes". A propuesta de Ana de Castro, se proclamó a Carmen de Burgos "socia benemérita" de la Cruzada. También había sido acogida poco antes en el "Grémio Carolina Angelo", logia encabezada por la propia Ana desde 1914 (Castro, 1914). En su regreso a Madrid, acompañaba a la autora su amiga Ana, a quien deseaba mostrar la vida madrileña y corresponder por tanta hospitalidad recibida.

Un año después, como amiga de la República portuguesa, Carmen vuelve a ser invitada por el Gobierno a un gran acontecimiento oficial, un nuevo momento histórico. Formó parte de la comitiva que el 6 de abril de 1921 salió en tren desde Lisboa para depositar en el Monasterio de Batalha los restos de dos soldados desconocidos, muertos uno en África y otro "en las trincheras francesas".

\section{LA CRUZADA DE MUJERES ESPAÑOLAS Y LA LIGA INTERNACIONAL}

A poco de regresar a Madrid en mayo de 1920, Carmen publicó en Heraldo una semblanza de Ana de Castro acompañada de su retrato, donde daba pública bienvenida a la "ilustre huésped" (25-V-1920), y siguió dando noticia de los actos celebrados en su honor en compañía de escritores, artistas y mujeres de los círculos feministas. La visita de Ana a Madrid no tuvo solo un tinte mundano. Su presencia guarda mayor significado si la relacionamos con el nacimiento en ese verano de la Cruzada de Mujeres Españolas. La reunión preparatoria se celebró el 1 de agosto, presidida por Carmen de Burgos, con la participación de mujeres destacadas: la doctora Concepción Aleixandre, presidenta de la Unión de Mujeres de España; la marquesa del Ter, presidenta del Consejo Nacional de Mujeres, Magdalena Santiago Fuentes, Josefa Barrera, Carmen Blanco y otras muchas. Con su asociación pretendían "influir en la legislación y trabajar en pro del mejoramiento social de la mujer" (Heraldo..., 2-VIII-1920).

Dos semanas después, Ana de Castro publicaba dos columnas en O Mundo (18-V-1920) glosando la creación de la nueva Cruzada y su filiación con la organización portuguesa, de cuyo nacimiento Carmen de Burgos había sido testigo directo en 1916. Y Carmen explicaba en su columna de $O$ Mundo que uno de los proyectos era pedir a las Cortes: el establecimiento del divorcio, la investigación de la paternidad, la igualdad de derechos entre hijos legítimos e ilegítimos, y la reforma del código en lo que discrimina a la mujer (16-VIII-1920).

La meta de Carmen es ante todo la igualdad legal entre hombres y mujeres, y conoce la necesidad de la organización política para su consecución. La Cruzada serviría para la ayuda práctica a la mujer y para la propaganda feminista; el partido Unión Republicana, para la acción política y la influencia en las leyes, y el 
Consejo Nacional de Mujeres, fundado el año anterior, para integrar el feminismo español en la Alianza Mundial. Un año después, el 30 de mayo de 1921, la Cruzada encabezó una acción pionera, la primera manifestación sufragista en la calle. Con Carmen de Burgos a la cabeza, recorrieron la Carrera de San Jerónimo repartiendo un manifiesto con los nueve puntos en que condensaban sus aspiraciones de igualdad legal y protección para la mujer. Llegaron al Congreso e hicieron entrega del documento a su Presidente.

Primero: Igualdad completa de derechos políticos, y, por tanto, ser electoras y elegibles.

Segundo: Igualdad de derechos civiles [...] urgentísima la revisión del Código civil.

Tercero: Que sean derogadas las leyes que abusivamente cierran a las mujeres determinadas carreras y empleos.

Cuarto: Que el Jurado sea constituido por individuos de los dos sexos.

Quinto: Igualdad con el hombre en lo que se refiere al Código penal.

Sexto: Que exista la investigación de la paternidad.

Séptimo: Que se consideren con iguales derechos ante la ley [...] los hijos legítimos e ilegítimos.

Octavo: [...] Centros de instrucción moral y cívica de la mujer.

Noveno: Que desaparezca, en virtud de una ley, la prostitución reglamentada y que se persiga.

Desde 1906, cuando Carmen promovió en Heraldo de Madrid aquella encuesta sobre el voto femenino, había intentado suscitar el debate y, como consecuencia, el interés de la sociedad sobre ese derecho. Es ahora el momento de recordar su tenacidad de tantos años para enfrentarse a una sociedad hostil que negaba a la mujer sus derechos cívicos.

Las dos Cruzadas, española y portuguesa, se integraron poco después en un proyecto más ambicioso, la Liga Internacional de Mujeres Ibéricas e Hispanoamericanas, que desde 1922 impulsaba en Nueva York la mexicana Elena Arizmendi, su secretaria general. En 1923 ofreció la presidencia a Carmen de Burgos, la figura emblemática en todos los ámbitos feministas de la cultura hispana. Proyectaron reunir la fuerza dispersa de las organizaciones feministas de todos los países Iberoamericanos. Feminismo Internacional (Nueva York) fue el órgano inicial de difusión de la Liga, pero el título pasó a ser sección en Revista de la Raza de Madrid desde el otoño de 1924.
En 1925, Carmen visitó México y Cuba para impartir conferencias sobre literatura y sobre feminismo en Universidades y centros cívicos. Su enfermedad obligó a suspender los actos que iba a presidir en Nueva York. Dos años después, emprendió la última travesía que la llevó a Perú, Bolivia y Chile, donde tuvo recibimientos muy calurosos, incluso por parte de los gobernantes.

\section{HACIA LA REPÚBLICA ESPAÑOLA Y LA ACCIÓN FINAL DE CARMEN DE BURGOS}

Antes de su viaje a América de 1927, publicó la autora La mujer moderna y sus derechos, que tuvo amplísima repercusión y podríamos considerar un libro histórico. El extenso conocimiento que Carmen ha acumulado a lo largo de los años en torno al problema femenino es ahora reelaborado y ofrecido desde los más diversos puntos de vista. Un documento de valor esencial para el conocimiento de la evolución social de la mujer. En el volumen que regaló a su amiga Ana escribió Carmen: "Para Ana de Castro Osorio, la más inteligente y buena de todas las mujeres. Con inmenso cariño (12 de abril 1928. Estoril)". ${ }^{14}$ También la gran amiga portuguesa escribió una hermosa reseña en que se revelaba la común visión del mundo:

a mulher espanhola [...] precisava dum livro como este, que fosse o seu guia no estudo do que tem sido o sexo feminino na sua acção social atravez dos séculos.

Não se trata dum livro feminista, nem mesmo se pode, em boa justiça classificar uma obra de combate, mas sim uma boa obra que se tornava indispensável para os paizes em que a idea duma humanidade composta de indivíduos igualados pelos direitos e pelos deveres, sem preocupações de sexos, está ainda muito embrionária ${ }^{15}$.

Al final del verano de 1928 visitó Madrid Ana de Castro, y Carmen publicó una amplia entrevista destacando su labor divulgadora de la literatura infantil portuguesa en la "Casa Editora para as Crianças". Ana respondía con su habitual humildad: "El único mérito que yo tuve fue el de ir a buscar hasta el pueblo, directamente, sus tradiciones y renovarlas [...] Ilevándola con el entusiasmo de un alma juvenil a todos los niños de Portugal, que hace treinta años la recibieron como un rocío del cielo" 16

Solo cabe ya resumir aquí el inmenso esfuerzo que emprendió Carmen de Burgos en 1931, al comienzo de la Segunda República Española; era el momento esperado, al que llegó casi sin aliento. Sin abandonar nunca la labor de escritora, regresaron los grandes te- 
mas sociales defendidos en incesantes campañas: el divorcio, la pena de muerte, el voto, la condena de la prostitución. Agotando sus últimas energías alcanzó las Navidades, que pasó junto a Ana en Estoril, su último refugio.

Su repentina pérdida, el 9 de octubre de 1932, interrumpió su campaña para ser diputada por el Partido Republicano Radical Socialista en las siguientes elecciones. La prensa nacional e internacional se hizo eco de su fallecimiento durante varios días; y entre los homenajes a su memoria, Ana de Castro escribía conmovida desde Lisboa:

Carmen de Burgos, a grande escritora espanhola [...] é um valor mundial que tôdas as mulheres devem respeitar, embora mesmo não concordem com a suas crenças e não estejam à altura do seu pensamento desanuviado e liberto de quaisquer dogmas e preconceitos sociais. [...] Amava mais os seus ideais do que a sua própria vida... E quem sabe se o seu grande e heróico sacrificio ficará ainda longos anos irreconhecido e inútil na sociedade, e principalmente entre as mulheres, ao progresso das quais se sacrificou! ${ }^{17}$

La propia Ana de Castro la sobrevivió poco más de dos años y, por causas distintas, sus respectivos países tendieron sobre ellas una capa de silencio que ha desdibujado la importancia histórica de ambas mujeres: Carmen de Burgos, más como escritora, Ana de Castro, más como política. En los dos casos, según queda reflejado, forman parte esencial de nuestra memoria.
1 "Lecturas para la mujer. Damas portuguesas", Diario Universal, 23 de abril de 1903.

2 "Femeninas. Mujeres portuguesas", $\mathrm{He}$ raldo de Madrid, 12 de octubre de 1910.

3 Aunque algunas referencias inducen a pensar que su primera visita se produjo en la primavera de 1915, los datos documentales, abrumadores, solo confirman su presencia desde el mes de agosto.

4 Sebastião Magalhães Lima (1850-1928). Figura del Partido Republicano, diputado constituyente en 1911, fue relator de la Constitución de la República. Ministro de Instrucción Pública en 1915. Fue Gran Maestre de la masonería portuguesa (1907-1928) y presidió el primer congreso feminista de París en 1878 (Congrés International des Droits des Femmes).

5 Joaquim Teófilo Fernandes Braga (184312924), profesor, escritor y político. En 1910 fue Jefe del Gobierno Provisional, y Presidente de la República entre mayo y octubre de 1915. Introductor del Positivismo en Portugal, fue figura principal de la Escuela de Coimbra y autor de una vasta obra poética y erudita.

6 Bernardino Luís Machado Guimarães (1851-1944). Catedrático en la Universidad de Coimbra. Gran Maestre en la masonería entre 1895 y 1899 . Ministro de Obras Públicas en 1893, contribuyó a elaborar una legislación protectora del trabajo de las mujeres y los menores. Miembro del Partido Republicano desde 1903, fue Ministro en varias ocasiones y Presidente del Gobierno en 1914. Presidente de la República desde octubre de 1915, fue expulsado a finales de 1917 por Sidónio Pais, y elegido nuevamente Presidente de la República en 1925, permaneció en el cargo hasta mayo de 1926. Dejó una extensa obra política y literaria.

7 Ese día, Heraldo de Madrid anunció su fallecimiento con una fotografía en portada en que aparecía junto a su amigo B. Machado.

8 El hecho, novedoso en la época, es evocado hoy con admiración por el poeta Antonio Osório de Castro, su devoto sobrino-nieto.

9 El gran poeta Camilo Pesanha solicitó en matrimonio a doña Ana, quien le respondió en una conmovedora carta la imposibilidad de aceptar por haberse prometido a Oliveira (Osório, 2005).

10 Años después, Carmen de Burgos evocó en una semblanza a la heroína ilustrada, que en 1799 fue ejecutada en Nápoles por sus ideales de libertad. "Eleonora de Fonseca Pimentel", La Esfera, № 728, Madrid, 17-XII-1927.

11 C. de Burgos, "Crónica literaria de Portugal. Eça de Queiroz y algunas anécdotas inéditas de su vida", Cosmópolis, № 21 , Madrid, septiembre de 1920, pp. 30-46.

12 Biblioteca Nueva (Imp. Sucesores de Rivadeneyra), Madrid, 1921.

13 Proceso no 15, Año 1919, Carmen de Burgos. "Arquivo Historico-Diplomatico do Ministério dos Negócios Estrangeiros" de Portugal, "Palácio das Necessidades", Lisboa.

14 El ejemplar con esa dedicatoria manuscrita se halla en la Biblioteca de la Comissão para a Igualdade e para os Direitos das Mulheres, en Lisboa.

15 Ana de Castro Osório, "A mulher moderna e os seus direitos", Revista de la Raza, № 155-156, agosto-septiembre de 1928.

16 Revista de la Raza, № 157-158, Madrid, octubre- noviembre de 1928, p. 10.

17 Ana de Castro Osório, "Acção feminista. Carmen de Burgos", Portugal Feminino, Año III, № 34, noviembre de 1932. 


\section{BIBLIOGRAFÍA}

Burgos, Carmen de (1916 a): Los míseros, en La Novela para Todos, Madrid, № XVII, 14 de julio de 1916. Con ilustraciones de Trillo.

Burgos, Carmen de (1916 b): Don Manolito, en Los Contemporáneos, Año VIII, № 416, 15 de diciembre de 1916. Ilustraciones de Gregorio Vicente.

Burgos, Carmen de (1916 c): Las Tricanas En La Novela Romántica, Madrid, Edic. Alfa, s.a., s. no.

Burgos, Carmen de (1916 d): Peregrinaciones (epílogo de Ramón Gómez de la Serna), Madrid, Impr. Alrededor del Mundo.

Burgos, Carmen de (1917): Mis viajes por Europa, Madrid, Sanz Calleja Editores, s.a.

Burgos, Carmen de (1920 a): La Flor de la Playa, en La Novela Corta, Madrid, Año V, № 231, 29-V-1920. Aparece reeditada en el volumen La Flor de la Playa y otras novelas cortas, Madrid, Castalia, 1989. Edición de Concepción Núñez Rey.

Burgos, Carmen de (1920 b): Los amores de Faustino, Madrid, La Novela Corta, Año V, № 254, 30-X-1920.
Burgos, Carmen de (1922 a): El suicida asesinado, Madrid, La Novela Corta, Año VII, № 339, 3-VI-1922.

Burgos, Carmen de (1922 b): El retorno Lisboa, Lusitania Editora, s.a.

Burgos, Carmen de (1923): El hastío del amor, En La Novela Corta, Madrid, Año VIII, № 410, 13 de octubre de 1923. Con ilustraciones de Bradley.

Burgos, Carmen de (1927): La mujer moderna y sus derechos, Valencia, Ed. Sempere.

Burgos, Carmen de (2012): Mis viajes por Europa, con epílogo de Ramón Gómez de la Serna. Edición, introducción y notas de C. Núñez Rey, Madrid, Edit. Catarata.

Castro Osório, Ana de (1914): Resposta a uma consulta, Lisboa, P. T. Assis.

Castro Osório, Ana de (1916): Estatutos da Cruzada das Mulheres Portuguesas, Lisboa, Imprensa Nacional.

Castro Osório, Ana de (1918): Comissão de Propaganda e Organização do Trabalho: discurso inaugural da Escola Profissional no 1 , Lisboa, Cruzada das Mulheres Portuguesas.
G. de la Serna, Ramón (1974): Automoribundia, Madrid, Ed. Guadarrama, Col. Punto Omega, 2 vols.

G. de la Serna, Ramón (1918): Pombo, Madrid, Imprenta del Mesón de los Paños.

Núñez Rey, Concepción (1992): Carmen de Burgos "Colombine" (1867-1932). Biografía y obra literaria, Madrid, Universidad Complutense.

Núñez Rey, Concepción (2005): Carmen de Burgos, "Colombine", en la Edad de Plata de la Literatura Española, Fundación J. Manuel Lara, Sevilla, 2005. Premio de Biografía "Antonio Domínguez Ortiz".

Núñez Rey, Concepción (2010): “Espacios y viajes en la vida y en la obra de Carmen de Burgos, Colombine". En Palomo Vázquez, Pilar, y varios: Carmen de Burgos, "Colombine" (1867-1932) en el periodismo y la literatura, revista Arbor (CSIC), Vol. 186, № extraordinario, junio de 2010.

Osório de Castro, Antonio (2005): O amor de Camilo Pesanha, Mafra, Edic. ELO. 